\title{
Psychological Well-Being, Mindfulness, and Impact of Stressful Events among Indian Teachers during COVID-19 Pandemic
}

\author{
Bhuvana Manohari Nataraj ${ }^{1 *}$, K. Jayasankara Reddy ${ }^{2}$
}

\section{ABSTRACT}

Lockdown efforts introduced as response to the coronavirus disease 2019 (COVID-19) pandemic has impacted various facets of life including the educational sector. This study focuses on teachers' mental health during this period. Research indicates positive mental health offsets negative impact of stress. The relationship of mental health assets such as psychological well-being, and mindfulness to COVID-19 event related stress is examined in this study. Teachers in India were approached through social media using snowball sampling to complete a survey. The survey consisted of the short version of Scales of Psychological Well-being (SPWB; Ryff, 1989), Cognitive and Affective Mindfulness Scale - Revised (CAMS-R; Feldman et al., 2007), and Impact of Event Scale - Revised (IES-R; Creamer, Bell, \& Failla, 2003). Results indicate that there is moderate negative correlation between psychological well-being and impact of event, and between mindfulness and impact of event. Psychological well-being and mindfulness and positively correlated. This indicates that presence of positive mental health components can imply lower stress response during the pandemic. Further study will help identify causal direction among the variables, which can inform mental health programs.

Keywords: Psychological capital, Traumatic stress, Resilience, Positive psychology

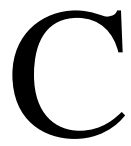
oronavirus disease 2019 (COVID-19) pandemic, caused by the severe acute respiratory syndrome coronavirus 2 (SARS-CoV-2), has brought with it not merely a health crisis, but crises in the social, economic, and psychological arenas as well. India has been under lockdown since 25th March owing to the COVID-19 pandemic. Educational institutions were shut down even before the lockdown came in place, with examinations suspended or postponed indefinitely, and uncertain reopening dates. Changes in expectations of teachers' roles, unfinished work with students, and reduced access to them have happened since. This is in addition to social isolation caused by physical distancing and forced home confinement, fear and uncertainty, and economic concerns that are already fallouts that many are experiencing during this time. There are personal differences in how stress is experienced even in times of crisis. This study was undertaken to understand the

${ }^{1}$ Doctoral candidate at the Department of Psychology, CHRIST (Deemed to be University), Bangalore, India. ORCiD - https://orcid.org/0000-0002-8868-1220

${ }^{2}$ Professor at the Department of Psychology, CHRIST (Deemed to be University), Bangalore, India.

ORCiD - https://orcid.org/0000-0002-6071-0472

*Corresponding Author

Received: June 14, 2021; Revision Received: August 03, 2021; Accepted: August 22, 2021

(C) 2021, Nataraj B. M. \& Reddy K. J.; licensee IJIP. This is an Open Access Research distributed under the terms of the Creative Commons Attribution License (www.creativecommons.org/licenses/by/2.0), which permits unrestricted use, distribution, and reproduction in any Medium, provided the original work is properly cited. 


\section{Psychological Well-Being, Mindfulness, and Impact of Stressful Events among Indian Teachers during COVID-19 Pandemic}

relationships among mindfulness, psychological well-being, and response to stressful events (COVID-19 lockdown in this case) among teachers in India.

Social distancing advisory was first issued by the Indian government on 17th March 2020, post the declaration of COVID-19 as pandemic by the World Health Organization (WHO) on 11th March 2020. Closure of educational institutions, among other establishments, was declared in the advisory (Press Information Bureau, 2020). While schools were declared closed for students, the teachers were expected to continue working. Bhat et al., (2020) report that this decision affected the sense of safety and morale of teachers as they were required to report to work place during the time of pandemic. After the declaration of nationwide lockdown that came in place from 25th March 2020, a slew of uncertainties emerged due to unfinished exams of students, job uncertainty, ambiguity about reopening dates, curriculum completion, welfare of students, and so on. This study was conducted during the second phase of nation-wide lockdown which began on 14th April 2020 and continued till 5th May 2020.

\section{Covid-19 and Mental Health: Traumatic Stress, Well-Being, and Mindfulness}

Surveys conducted show that stress, depression, feeling of loneliness, anxiety, and sleep disturbances are some of the areas of mental health that have been impacted by the pandemic (Rajkumar, 2020). In a study conducted in China (Liu et al., 2020), it was found that people experienced post-traumatic stress symptoms in the wake of the COVID-19 situation. Women were found to have a greater propensity than men in experiencing these symptoms, which include re-experiencing or intrusion, negative cognitive alteration, and hyperarousal. This pandemic and associated large-scale, sudden changes in ways of living can be construed as a traumatic event impacting mental health globally.

In this scenario, it is important to understand those factors and processes that enhance mental health (Holmes et al., 2020). Mental health allows for resilience and effective coping mechanisms to overcome challenges during this period. Furthermore, lack of mental health can be detrimental in this pandemic situation, as poorer mental health can lead to increased stress leading to compromised immunity, and decreased health-promoting preventative behavior (Torales, et al., 2020). In a study conducted among older adults, it was found that resilience moderated the impact of stressful life events on psychological well-being (de Paula Couto, Koller, \& Novo, 2011).

Psychological well-being (Ryff, 1989) represents positive or wholesome functioning of individuals, and consists of the following dimensions: positive relationships with others, personal growth, autonomy, environmental mastery, self-acceptance, and purpose in life. Studies have shown that psychological well-being is indicative of psychological capital and resilience (Fullagar \& Mills, 2010), and has often found to enhance stress-combating skills (Ryff et al., 2006). Thus, psychological well-being can be seen as indicative of good mental health, and can act as a buffer during stressful events.

Mindfulness has been used as a stress-reduction tool since the inception of Kabat-Zinn's (1982) Mindfulness-Based Stress Reduction (MBSR) program, and has been used in various therapeutic and personal development settings. Kabat-Zinn (1990) describes mindfulness as "moment-by-moment awareness, the complete 'owning' of each moment of your experience, good, bad, or ugly." Shapiro et al., (2006) present three axioms or core components of mindfulness: intention, attention, and attitude - "on purpose (intention) 


\section{Psychological Well-Being, Mindfulness, and Impact of Stressful Events among Indian Teachers during COVID-19 Pandemic}

paying attention (attention) in a particular way (attitude)." Thus, at the core of it, mindfulness can be understood as intentionally paying attention to one's experiences in the present moment, with openness, acceptance, and non-judgement towards those experiences. In a study on the effectiveness of mindfulness-based intervention for public school teachers in Canada (Taylor et al., 2015), it was found that the program helped increase the tendency to forgive, self-efficacy beliefs, and reduce occupational stress. Another study conducted as part of Community Approach to Learning Mindfully (CALM) by Harris et al., (2015) found that teachers who underwent yoga and mindfulness intervention showed an increase in mindfulness, enhanced emotional regulation, a decrease in stress, and an overall increase in well-being.

\section{Current Study}

This study sought to explore the relationships of mindfulness to PWB, and to stress response to COVID-19 event; and that between PWB and stress response among teachers in India. A study conducted by Ryff et al. (2006), suggests that the presence of well-being does not necessarily mean the absence of ill-being, and vice versa. While some biological correlates mirror, certain other correlates do not. This indicates that well-being can be present alongside ill-being at the same time. Studies show that mindfulness can impact both illbeing and well-being. Thus, the objectives of this study ate to examine the relationship between positive psychological functioning components of psychological well-being and mindfulness, and also to examine the relationship of these positive components to stress impact of COVID-19 pandemic event.

\section{METHODOLOGY}

\section{Sample}

82 individuals participated in the survey, of whom 71 were female $(87 \%)$, 10 were male $(12 \%)$, and $1(1 \%)$ undisclosed. People from 14 Indian states participated. However, the majority are from Karnataka (51\%), followed by Tamil Nadu (17\%), and the rest 32\% distributed among the other 12 states. $29 \%$ of the respondents were teachers in tertiary education (college/university), 38\% in high and higher secondary schools, $29 \%$ in middle, primary, and pre-schools, $4 \%$ in other educational categories. $17 \%$ of the participants have completed under-graduation, $68 \%$ post-graduation, and $15 \%$ doctorate. Most of them were full-time teachers $(83 \%), 11 \%$ part-time teachers, and $6 \%$ were limited-period contract employees.

\section{Instruments}

Self-report tools were used to assess PWB, mindfulness, and stress response to event.

- Demographic Details: Participant demographic details such as age, gender, marital status, geographical location, living situation, educational qualification, work information, and the like were collected. Participants were also asked and open question on what their biggest concern was during this pandemic.

- Scales of Psychological Well-Being (SPWB; Ryff, 1989): The 3-item scales of psychological well-being were used. This is the short version used by the author in large-scale surveys. With three items each to six dimensions of well-being, there are a total of 18 items. Each item contains a statement to which participants are required to respond how strongly they agree or disagree with the statement $(1$ - strongly disagree, 2 - disagree somewhat, 3 - disagree slightly, 4 - agree slightly, 5 - agree somewhat, 6 - strongly agree). Scores on this scale can range from 18 to 108, and higher the score, higher the measure of PWB. 
- Cognitive and Affective Mindfulness Scale - Revised (CAMS-R; Feldman et al., 2007): CAMS-R is a brief tool to assess mindfulness, which is not limited by specific school or type of mindfulness meditation as broader concept mindfulness was taken into account in the construction of this tool. There are 10 items in this scale, with each item containing a statement about self, to which one responds how often the statement is true for them (1 - rarely/not at all, 2 - sometimes, 3 - often, 4 - almost always). Scores on this scale will lie between 10 and 40, with higher score indicating more mindfulness.

- Impact of Events Scale - Revised (IES-R; Creamer, Bell, and Failla, 2003): This 22-tem scale assesses traumatic stress on three dimensions viz., intrusion (8 items), avoidance ( 8 items), and hyperarousal (6 items). This tool was administered asking participants to complete it with reference to the COVID-19 lockdown event. Each item is marked on Likert scale ranging from 0 to $4(0-$ not at all, $1-$ a little bit, $2-$ moderately, 3 - quite a bit, 4 - extremely) on how each statement was true of them. Minimum score possible on this scale is 0 , and the maximum is 88 , and higher the score greater the traumatic stress response to the event.

\section{Procedure}

Data was collected through an online survey using Google Forms, through snowball sampling procedure. Link to the survey was circulated through social media platforms such as WhatsApp, Facebook, and Instagram. Participants were provided with the required information regarding the purpose and limitations of the study, and only consenting participants completed the survey. Data was collected over a period of two weeks, between 18th April 2020 to $2^{\text {nd }}$ May 2020.

\section{RESULTS}

Table No. 1 Descriptive Statistics of Psychological Well-being, Mindfulness, and Impact of Event

\begin{tabular}{|c|c|c|c|c|c|}
\hline Scales & $\mathbf{N}$ & Mean & SD & Min. Score & Max. Score \\
\hline SPWB & \multirow{6}{*}{82} & 78.67 & 9.90 & 52 & 97 \\
\hline CAMS-R & & 28.83 & 4.73 & 19 & 37 \\
\hline IES-R & & 22.29 & 14.61 & 0 & 71 \\
\hline Intrusion & & 7.35 & 5.84 & 0 & 27 \\
\hline Avoidance & & 10.17 & 6.69 & 0 & 27 \\
\hline Hyperarousal & & 4.77 & 3.93 & 0 & 17 \\
\hline
\end{tabular}

Mean and standard deviations were computed for the variables, and for the subscales of IESR. Dimensions of PWB were not computed individually as there were only three items per dimension in the scale, so the author decided to take total PWB score for this study. ShapiroWilk test of normality indicated that the scores of all the three scales were not normally distributed. Hence, Spearman's Rho method was used to measure the relationship among the variables.

Descriptive data of the scales administered are presented in Table 1. A total of 82 participants completed all the three scales. Mean score of PWB is 78.67, with standard deviation of 9.9, and the minimum score was 52, and the maximum was 97. Mindfulness scale had a mean score of 28.83 with 4.73 standard deviation, with scores ranging between 19 and 37. Overall mean score on impact of events was 22.3 with standard deviation of 14.6, 


\section{Psychological Well-Being, Mindfulness, and Impact of Stressful Events among Indian Teachers during COVID-19 Pandemic}

and minimum and maximum scores were 0 and 71 . The three subscales - intrusion, avoidance, and hyperarousal - had mean scores of 7.35, 10.17, and 4.77 respectively, with standard deviations of 5.84, 6.69, and 3.93. Minimum score was 0 for all the three subscales, and the maximum were 27,27 , and 17 respectively.

Table 2. Spearman's Rank Correlation among PWB, Mindfulness, and Impact of Event

\begin{tabular}{|l|l|l|l|l|l|}
\hline & $\begin{array}{l}\text { Impact of } \\
\text { Event }\end{array}$ & Intrusion & Avoidance & Hyperarousal & Mindfulness \\
\hline PWB & $-.30^{* *}$ & $-.31^{* *}$ & $-.19^{*}$ & $-.31^{* *}$ & $.31^{* *}$ \\
\hline Mindfulness & $-.31^{* *}$ & $-.22^{*}$ & $-.23^{*}$ & $-.42^{* * *}$ & \\
\hline
\end{tabular}

Weak and moderate correlations were found among the variables. PWB was found to have moderate negative correlation with impact of event scale $(\operatorname{rs}(80)=-.30, \mathrm{p}=.003)$, and two of the subscales including intrusion $(\mathrm{rs}(80)=-.31, \mathrm{p}=.002)$ and hyperarousal $(\mathrm{rs}(80)=-$ $.31, \mathrm{p}=.003)$. There was a weak negative correlation with the avoidance subscale $(\mathrm{rs}(80)=-$ $.19, \mathrm{p}=.046)$.

Mindfulness was also found to have moderate negative correlation with IES-R $(\operatorname{rs}(80)=$ $.31, \mathrm{p}=.002)$, and hyperarousal subscale $(\mathrm{rs}(80)=-.42, \mathrm{p}<.001)$. The correlation was weak with intrusion $(\mathrm{rs}(80)=-.22, \mathrm{p}=.026)$, and avoidance $(\mathrm{rs}(80)=-.23, \mathrm{p}=.018)$ subscales. The relationship between PWB and mindfulness was moderate positive $(\operatorname{rs}(80)=.31, \mathrm{p}=$ $.002)$.

One-tailed test was used to assess significance of the correlation as the hypotheses in this study are directional.

\section{DISCUSSION}

This study set out to explore the relationship among psychological well-being, mindfulness, and COVID-19 related event stress among teachers in India. In line with theory and research, the findings show that there is a negative relationship with stress response to COVID-19 lockdown to both PWB and mindfulness, and a positive relationship between PWB and mindfulness. Taylor et al., (2015) also found that increasing mindfulness among teachers enabled them to enhance their emotion regulation, and increased their self-efficacy in managing emotions, which contributed to reduced stress. This study also showed that increase in mindfulness enhanced prosocial behaviors such as forgiveness and compassion, which are indicative of well-being. Vazi et al., (2013) found that well-being - both subjective and psychological - contributed significantly to the variance in stress among teachers in South Africa.

While the overall relationship strength between mindfulness and event-related stress is moderate, there are differences pertaining to the domains of event-related stress. There is a stronger negative correlation between mindfulness and hyperarousal domain of event-related stress, compared to intrusion and avoidance domains. Intrusion is indicative of intrusive thoughts and emotions, and avoidance is the pushing away of these intrusive thoughts and emotions. Hyperarousal means being in an agitated, flight-or-fight, state continually (Weiss, 2007). The mechanism of mindfulness proposed by Hölzel et al., (2012), talks about attention regulation, body awareness, emotion regulation, and change in perspective of self as distinct and interacting components of mindfulness. At a more visceral level, attention 


\section{Psychological Well-Being, Mindfulness, and Impact of Stressful Events among Indian Teachers during COVID-19 Pandemic}

regulation and body awareness acts as a bio-feedback mechanism which enables reducing stress response or hyperarousal. Intrusion and avoidance require higher-order cognitive functioning, which is also addressed through the metacognitive role of mindfulness. This could be indicative that attention regulation towards body awareness (sixth sense as proposed by Siegel, 2007), happens more readily than towards thoughts and emotions (seventh sense, Siegel, 2007).

\section{Limitations and Suggestions for Future Direction}

There are limitations to this study. Due to the time-bound nature of the event, shorter surveys had to be used. Lengthier scales would have provided more nuanced results among dimensions of the variables. While the use of non-parametric analysis tool allowed for establishing the relationship among the variables, snow-balling sampling procedure did not allow for representative sample, or normally distributed data. This limits how much the results can be generalized.

Inclusion of more preventative variables that impact event-related stress can help understand the mechanism of effective coping, and resilience, which can inform positive mental health strategies. Increasing the number of participants in the future will allow for deeper analysis of the relationship between the variables, and generalizing the results. This is a correlational study, and as such, causation cannot be established. Controlled experiments will add to our understanding of these variables.

\section{REFERENCES}

Bhat, R., Singh, V. K., Naik, N., Kamath, C. R., Mulimani, P., \& Kulkarni, N. (2020). COVID 2019 outbreak: The disappointment in Indian teachers. Asian journal of psychiatry, 50, 102047. https://doi.org/10.1016/j.ajp.2020.102047

de Paula Couto, M.C.P., Koller, S.H. \& Novo, R. Stressful Life Events and Psychological Well-being in a Brazilian Sample of Older Persons: The Role of Resilience. Ageing international 36, 492-505 (2011). https://doi.org/10.1007/s12126-011-9123-2

Culbertson, S. S., Fullagar, C. J., \& Mills, M. J. (2010). Feeling good and doing great: the relationship between psychological capital and well-being. Journal of occupational health psychology, 15(4), 421-433. https://doi.org/10.1037/a0020720

Garland, E., Gaylord, S., \& Park, J. (2009). The role of mindfulness in positive reappraisal. Explore (New York, N.Y.), 5(1), 37-44. https://doi.org/10.1016/j.explore.2008.10.001

Harris, A. R., Jennings, P. A., Katz, D. A., Abenavoli, R. M., \& Greenberg, M. T. (2016). Promoting stress management and wellbeing in educators: Feasibility and efficacy of a school-based yoga and mindfulness intervention. Mindfulness, 7(1), 143-154.

Holmes, E. A., O'Connor, R. C., Perry, V. H., Tracey, I., Wessely, S., Arseneault, L., ... \& Ford, T. (2020). Multidisciplinary research priorities for the COVID-19 pandemic: a call for action for mental health science. The Lancet Psychiatry.

Hölzel, B. K., Lazar, S. W., Gard, T., Schuman-Olivier, Z., Vago, D. R., \& Ott, U. (2011). How Does Mindfulness Meditation Work? Proposing Mechanisms of Action from a Conceptual and Neural Perspective. Perspectives on psychological science: a journal of the Association for Psychological Science, 6(6), 537-559. https://doi.org/10.1177/1745691611419671

Jennings, P. A. (2015). Mindfulness for teachers: Simple skills for peace and productivity in classroom. New York, NY: W. W. Norton \& Co. 


\section{Psychological Well-Being, Mindfulness, and Impact of Stressful Events among Indian Teachers during COVID-19 Pandemic}

Kabat-Zinn, J. (1982). An outpatient program in behavioral medicine for chronic pain patients based on the practice of mindfulness meditation: Theoretical considerations and preliminary results. General hospital psychiatry, 4(1), 33-47.

Kabat-Zinn, J. (1990). Full Catastrophe Living: Using the wisdom of body and mind to face stress, pain, and illness. New York, NY: Bantam Dell.

Liu, N., Zhang, F., Wei, C., Jia, Y., Shang, Z., Sun, L., Wu, L., Sun, Z., Zhou, Y., Wang, Y., \& Liu, W. (2020). Prevalence and predictors of PTSS during COVID-19 outbreak in China hardest-hit areas: Gender differences matter. Psychiatry research, 287, 112921. https://doi.org/10.1016/j.psychres.2020.112921

Press Information Bureau. (2020). Ministry of Health Issues Comprehensive Advisory on Social Distancing. Retrieved from https://pib.gov.in/PressReleseDetail.aspx?PRID=1606637

Rajkumar R. P. (2020). COVID-19 and mental health: A review of the existing literature. Asian journal of psychiatry, 52, 102066. Advance online publication. https://doi.org/10.1016/j.ajp.2020.102066

Ryff, C. D. (1989). Happiness is everything, or is it? Explorations on the meaning of psychological well-being. Journal of Personality and Social Psychology, 57(6), 10691081. doi:10.1037/0022-3514.57.6.1069

Ryff, C. D., Dienberg Love, G., Urry, H. L., Muller, D., Rosenkranz, M. A., Friedman, E. M., Davidson, R. J., \& Singer, B. (2006). Psychological well-being and ill-being: do they have distinct or mirrored biological correlates? Psychotherapy and psychosomatics, 75(2), 85-95. https://doi.org/10.1159/000090892

Shapiro, S. L., Carlson, L. E., Astin, J. A., \& Freedman, B. (2006). Mechanisms of mindfulness. Journal of clinical psychology, 62(3), 373-386. https://doi.org/10.1002/jclp.20237

Siegel, D. J. (2007). The mindful brain: Reflection and attunement in the cultivation of wellbeing. New York, NY: W. W. Norton.

Taylor, C., Harrison, J., Haimovitz, K., Oberle, E., Thomson, K., Schonert-Reichl, K., \& Roeser, R. W. (2016). Examining ways that a mindfulness-based intervention reduces stress in public school teachers: A mixed-methods study. Mindfulness, 7(1), 115-129. https://doi.org/10.1007/s12671-015-0425-4

Torales, J., O’Higgins, M., Castaldelli-Maia, J. M., \& Ventriglio, A. (2020). The outbreak of COVID-19 coronavirus and its impact on global mental health. International Journal of Social Psychiatry, 66(4), 317-320. https://doi.org/10.1177/0020764020915212

Vazi, M. L., Ruiter, R. A., Van den Borne, B., Martin, G., Dumont, K., \& Reddy, P. S. (2013). The relationship between wellbeing indicators and teacher psychological stress in Eastern Cape public schools in South Africa. SA Journal of Industrial Psychology, 39(1), 00-00.

Weiss, D. S. (2007). The Impact of Event Scale: Revised. In J. P. Wilson \& C. S.-k. Tang (Eds.), International and cultural psychology. Cross-cultural assessment of psychological trauma and PTSD (p. 219-238). Springer Science + Business Media. https://doi.org/10.1007/978-0-387-70990-1_10

\section{Acknowledgement}

The authors appreciate all those who participated in the study and helped to facilitate the research process.

\section{Conflict of Interest}

The author(s) declared no conflict of interest. 
Psychological Well-Being, Mindfulness, and Impact of Stressful Events among Indian Teachers during COVID-19 Pandemic

How to cite this article: Nataraj B. M. \& Reddy K. J. (2021). Psychological Well-Being, Mindfulness, and Impact of Stressful Events among Indian Teachers during COVID-19 Pandemic. International Journal of Indian Psychology, 9(3), 1017-1024. DIP:18.01.093.20210903, DOI:10.25215/0903.093 